\title{
Preservation of the Anterior Branch of the Great Auricular Nerve during Benign Parotid Neoplasm Excision
}

\author{
Khalid B. Alghamdi, MD, FRCSC \\ Department of Otorhinolaryngology and Head and Neck Surgery \\ Faculty of Medicine, King Abdulaziz University, Jeddah, Saudi Arabia
}

\section{Correspondence}

Dr. Khalid B. Alghamdi

P.O. Box 80215, Jeddah 21589, Saudi Arabia

e.M: kbalghamdy@kau.edu.sa

Submission: 16 Dec. 2015

Accepted: 09 Jan. 2016

\section{Citation}

Alghamdi KB. Preservation of the anterior branch of the great auricular nerve during benign parotid neoplasm excision. JKAU Med Sci 2016; 23 (2): 15-19. DOI: 10.4197/Med. 23.2.2

\begin{abstract}
The aim of this study is to examine the impact of the process of preservation of both divisions of great auricular nerve on patients' quality of life. This is a retrospective study conducted at King Abdulaziz University Hospital after receiving formal consent from the research ethics committee. For the analysis, charts of all patients who underwent partial parotidectomies (superficial parotidectomies) for benign neoplasm were evaluated and the results were validated. A total 45 cases of superficial parotidectomies were observed, out of which, 15 had preservation of the great auricular nerve (anterior and posterior divisions), and numbness and feeling of well-being were better in this group as compared to the great auricular nerve anterior division sacrifice group. The influence of great auricular nerve sacrifice morbidity on patient's quality of life varied. Great auricular nerve morbidity requires further efforts to be made in order to preserve the posterior and anterior branches of this nerve when possible and in the case of the benign lesion, it is considered more suitable.
\end{abstract}

\section{Keywords}

Parotidectomy; Great auricular nerve; Anesthesia; Hypoesthesia

\section{Introduction}

$A$ mong the cutaneous branches of the cervical plexus, great auricular nerve (GAN) is the largest of all. The ventral rami of $\mathrm{C} 2$ and $\mathrm{C} 3$ spinal nerves are the point from which it originates and emerges on the horizontal surface of the sternocleidomastoid muscle by twisting around its posterior border (Erb's point). It extends deep to the platysma muscle, towards the apex of the parotid gland where it is separated into anterior and posterior branches. Anterior branch along with the external jugular vein goes obliquely upward and forward on the surface of the sternocleidomastoid muscle and is sensitive to facial skin over the parotid gland and part of the ear lobule, whereas the posterior branch supplies to the skin over the mastoid process, back of the auricle, lobule and a portion of the scalp ${ }^{[1]}$.

Various cranial nerves are linked with the GAN and communicate in such a way that a small twig (or several small twigs) from the anterior branch is directed into the substance of the parotid gland and is joined to the facial nerve, especially the marginal mandibular nerve ${ }^{[2,3]}$. The auricular branch of the vagus nerve and the posterior auricular branch of the facial nerve are linked with the posterior branch which communicates with them ${ }^{[1]}$. 
Parotid surgery is a commonly adopted procedure worldwide, and more than $80 \%$ types of tumors are due to benign lesions. As a result of postoperative care and advancements in the surgical approaches, complication rates decrease, which in turn, enhances the quality of life. It has been observed for a long time that postoperative anesthesia or hypoesthesia around the ear and the face ${ }^{[4-10]}$ is minimized through preservation of the GAN posterior division. Recently, the role of preservation of the anterior division of the GAN in order to improve the quality of life and standard of care has been considered. In this study, an

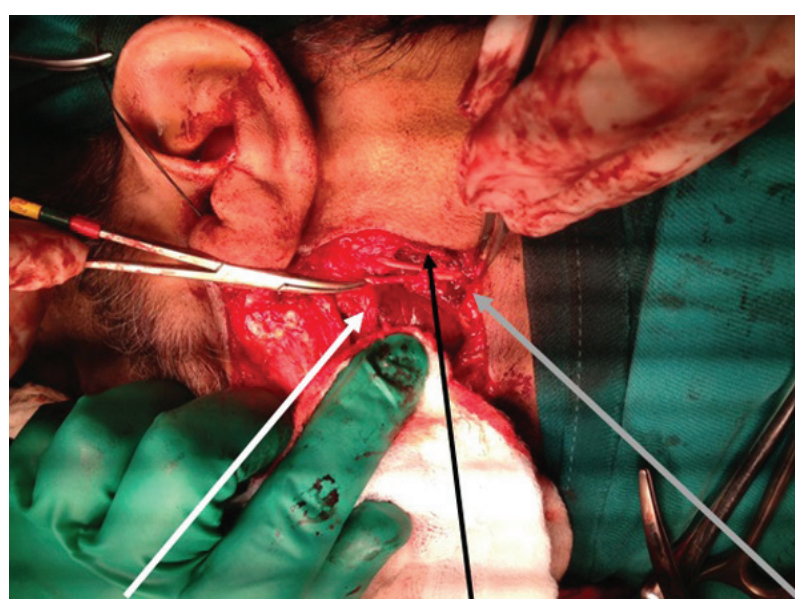

Figure 1. The white arrow is the anterior division; black arrow is the post-division; gray arrow is the main trunk.

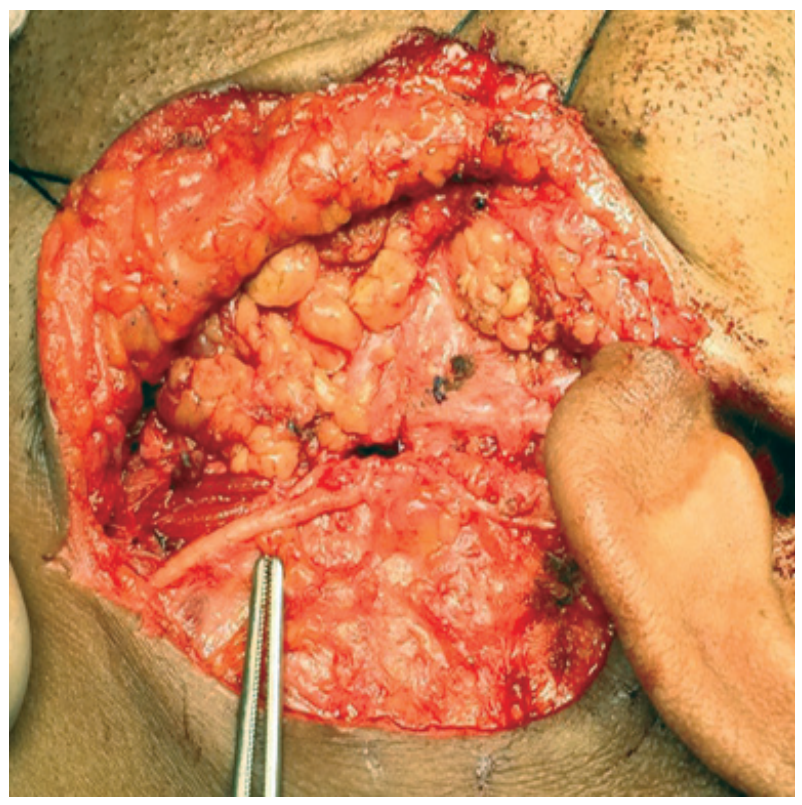

Figure 2. The main nerve main trunk. attempt has been made to determine the feasibility of modifying surgical dissection and to evaluate whether it is worth the effort or not.

\section{Technique}

The main trunk of the GAN is recognized after flap elevation and followed up as it ascends to the lateral surface of the Sternocleidomastoid muscle. The nerve is divided below the ear lobule where the posterior division (larger and more defined) can be easily saved, released from the parotid fascia and retracted posteriorly from the surgical field. The division not easily dissected is the anterior division, which is small. Soon after emerging from the main trunk, it starts to divide and penetrate into the parotid fascia. The main part of this branch can be released, retracted posteriorly with its counterpart, and saved by using a fine dissecting instrument (Fig. 1). This technique takes 5-10 extra minutes of the whole surgical time but gives the desired results (Figs. 2 and 3).

\section{Material}

For data collection and analysis, this retrospective cohort study collected the charts of all patients who had undergone partial or superficial parotidectomies and received approval of the Ethics committee. During the period 2005-2015, only cases of benign parotid lesions were studied.

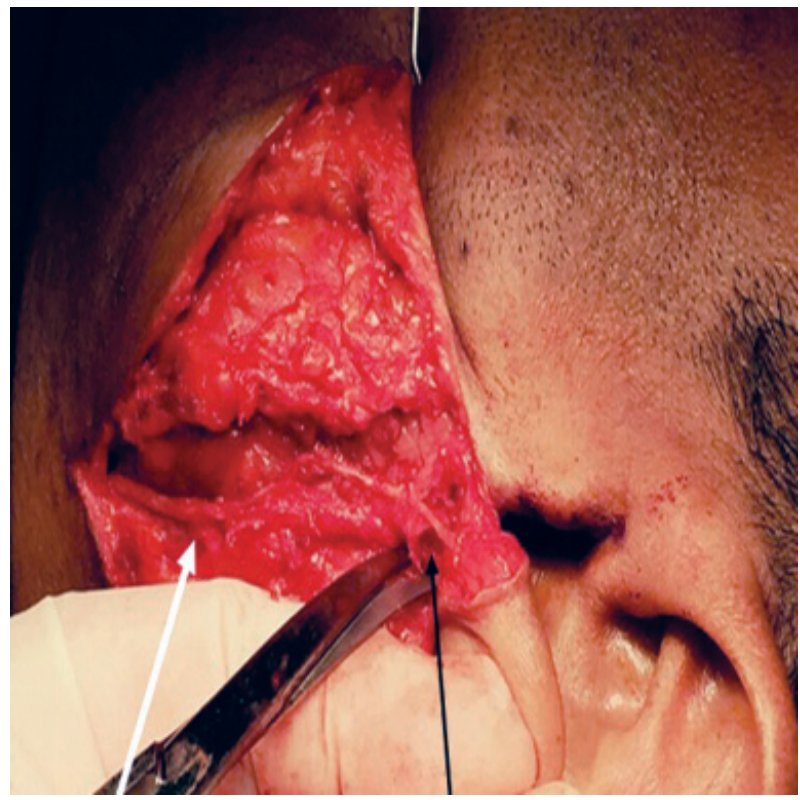

Figure 3. The white arrow is the main trunk; the black arrow is the anterior division looping around the auricle. 


\section{Results}

A total of 45 cases of superficial parotidectomies were examined, which included 27 females and 18 males (Table 1). Age of the patients ranged from $14-70$, however, the average age group was 43 years. Although there were 4 (8.8\%) cases of Warthrin's tumor, 2 (4.4\%) cases of oncocytoma and one (2.2\%) case of chronic proctitis, the majority of the cases were of pleomorphic adenomas (84.4\%) amounting to a total of 38 cases. The average number of visits was six with the follow-up period being 48 months.

All patients were inquired about the incidence of numbness around the auricle and the nearby parotid region, accidental burns, pain and injuries during shaving or earring piercing.

In both groups, in the first postoperative month, all patients experienced numbness around the parotid region and the anterior ear lobule $(100 \%)$, whereas, in the third month, the group which followed preservation of the anterior division reported better sensation and feeling around that area (group A). Compared to the other group (group B), where numbness and abnormal sensation persisted in 7 (23.3\%) patients. (Table 2).

\section{Discussion}

Many articles have stressed on the value of preserving the GAN posterior division in detail; therefore it is not an unfamiliar topic of discussion ${ }^{[4-10]}$. Patel et al. ${ }^{[10]}$ utilized Quality of Life Survey in their comprehensive cohort study which showed that in the area of the GAN sacrifice, $57 \%$ of the patients involved in the study had some altered sensation and the symptoms were at their peak in the first year postoperatively. However,

Table 1. Patients number according to nerve preservation.

\begin{tabular}{|l|c|c|}
\hline Gender & $\begin{array}{c}\text { Sparing Both } \\
\text { Divisions of GAN } \\
\text { (A) }\end{array}$ & $\begin{array}{c}\text { Sparing Posterior } \\
\text { Division of GAN } \\
\text { (B) }\end{array}$ \\
\hline Males & 5 & 13 \\
Females & 10 & 17 \\
\hline Total & & 45 \\
\hline
\end{tabular}

ABBRV: $G A N=$ Great auricular nerve

Table 2. Postoperative sensation.

\begin{tabular}{|l|c|c|}
\hline Gender & $\begin{array}{c}\text { Normal Sensation } \\
\text { after } \\
\text { 3 months (Group A) }\end{array}$ & $\begin{array}{c}\text { Altered Sensation after } \\
\text { 3 months (Group B) }\end{array}$ \\
\hline Males & 5 & 2 \\
Females & 10 & 5 \\
\hline
\end{tabular}

despite improvement in the severity of symptoms with time, some patients even complained about the loss of sensation or the altered feeling in and around the ear and the infra-auricular area ${ }^{[10]}$. The review presented by Koch et al. ${ }^{[11]}$ based on 492 patients who underwent different types of parotid surgeries for benign parotid surgery, reported that the incidence of numbness and altered sensation around the parotid region and the auricle was $58.8 \%$. However, in patients who underwent superficial parotidectomies, the duration of the numbness was longer as compared to the other types of surgeries (total parotidectomies and partial superficial parotidectomies) ${ }^{[11]}$.

A prospective controlled, double-blind study conducted by Hui et al. ${ }^{[12]}$ showed that the outcome was far better if the posterior division was preserved ${ }^{[12]}$. Moretti and colleagues ${ }^{[13]}$ illustrated the superior benefit of preserving a major part of the anterior division of GAN with improved quality of life and surgical outcome ${ }^{[13]}$. However, loss of function (sensation) was observed at least in the first 3 postoperative months in all the studies published ${ }^{[4-13]}$ including this study which could be attributed to retraction and nerve stretch injuries. One prospective controlled study showed that although the GAN main trunk was identified to be divided into three branches, and the anterior division penetrating the parotid fascia was sacrificed in all cases, maximum preservation of the GAN fibers resulted in a better outcome regarding sensation ${ }^{[14]}$. The idea of preserving the maximum fibers of the GAN may result in better outcome regardless of the difference in branch nomenclature. Although this is a retrospective study based on small sample size which is not enough to make solid conclusions, but there is some evidence, suggesting that maximum preservation of the nerve fibers well be an added benefit to patients' satisfaction. Finally, if the capsule is tethered to the nerve, it should be taken into consideration that the tumor capsule should not be violated in an effort to save any branch of the GAN.

\section{Conclusion}

Further efforts are needed to preserve the maximum GAN anterior and posterior fibers with improved quality of life and standard of care in benign parotid surgery. There is a need of a controlled prospective study in the near future to further examine the significance of preserving the anterior division of the GAN. 


\section{Conflict of Interest}

The author has no conflict of interest.

\section{Disclosure}

The author did not receive any type of commercial support either in forms of compensation or financial for this study. The author has no financial interest in any of the products or devices, or drugs mentioned in this article.

\section{Ethical Approval}

Obtained.

\section{References}

[1] Berry M, Bannister LH, Stranding SM. Nervous system. In: Gray's Anatomy. Bannister LH, Berry MM, Collins P, Dyson M, Dussek JE, Ferguson MWJ, eds. 38 ${ }^{\text {th }}$ ed. New York: Churchill Livingston, 1995. 901-1937.

[2] Srinivasa RS, Satheesha NB, Kumar MRB, Swamy RS. Communication of the anterior branch of the great auricular nerve with the cervical branch of facial nerve and its variant nerve endings deep in the parotid gland. Int J Morphol 2012; 30(3): 840-842.

[3] Brennan PA, Al Gholmy M, Ounnas H, Zaki GA, Puxeddu $\mathrm{R}$, Standring S. Communication of the anterior branch of the great auricular nerve with the marginal mandibular nerve: A prospective study of 25 neck dissections. Br J Oral Maxillofac Surg 2010: 48(6): 431-433.

[4] Leverstein H, van der Wal JE, Tiwari RM, van der Waal I, Snow GB. Surgical management of 246 previously untreated pleomorphic adenomas of the parotid gland. $\mathrm{Br} J$ Surg 1997; 84(3): 399-403.

[5] Owen ER, Banerjee AK, Kissin M, Kark AE. Complications of parotid surgery: the need for selectivity. Br J Surg 1989; 76(10): 1034-1035.

[6] Brown JS, Ord RA. Preserving the great auricular nerve in parotid surgery. Br J Oral Maxillofac Surg 1989; 27(6): 459466.

[7] Christensen NR, Jacobsen SD. Parotidectomy: preserving the posterior branch of the great auricular nerve. J Laryngol Otol 1997; 111(6): 556-559.

[8] Schultz JD, Dodson TB, Meyer RA. Donor site morbidity of greater auricular nerve graft harvesting. J Oral Maxillofac Surg 1992; 50(8): 803-805.

[9] Ryan WR, Fee WE Jr. Great auricular nerve morbidity after nerve sacrifice during parotidectomy. Arch Otolaryngol Head Neck Surg 2006; 132(6): 642-649.

[10] Patel N, Har-El G, Rosenfeld R. Quality of life after great auricular nerve sacrifice during parotidectomy. Arch Otolaryngol Head Neck Surg 2001; 127(7): 884-888.
[11] Koch M, Zenk J, Iro, H. Long-term results of morbidity after parotid gland surgery in benign disease. Laryngoscope 2010; 120(4): 724-730.

[12] Hui Y, Wong DSY, Wong LY, Ho WK, Wei WI. A prospective controlled double-blind trial of great auricular nerve preservation at parotidectomy. Am J Surg 2003; 185(6): 574-579.

[13] Moretti A, Citraro L, Petruci AG, Di Giovanni P, Di Mauro R, Giacomini PG. Great auricular nerve presrvation in parotid surgery: rationale and long-term result insights. Eur Arch Oto-Rhino-Laryngol 2015; 72(11): 3515-3520.

[14] Vieira MBM, Maia AF, Ribeiro JC. Randomized prospective study of the validity of the great auricular nerve preservation in parotidectomy. Arch Otolaryngol Head Neck Surg 2002; 128(10): 1191-1195. 


\title{
الحفاظ على الفرع الأمامي من العصب السمعي العظيم في جراحات الغدة النكافية

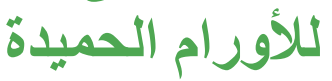

\author{
خالا ب م الغامدي \\ قسم الأنف والأن مالن والحنجرة والرأس والعنق، كلية الطب \\ جامعة الملك عبد العزبيز \\ جلة ـ المملكة العربية السعودية العبية
}

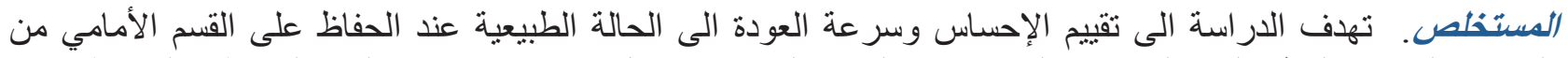

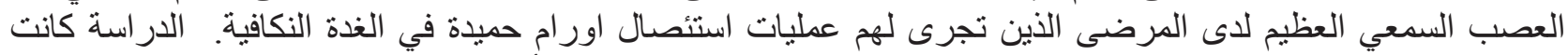

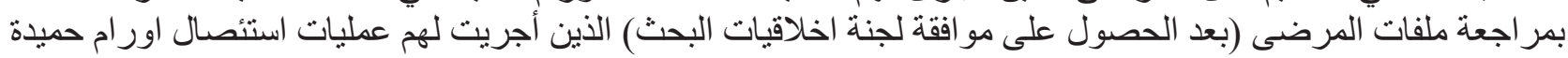

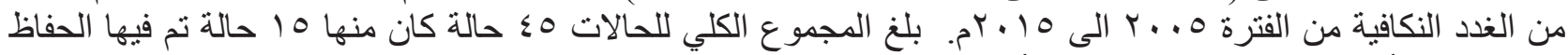

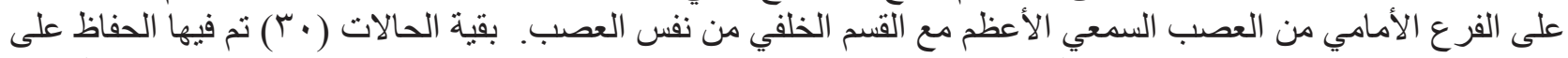

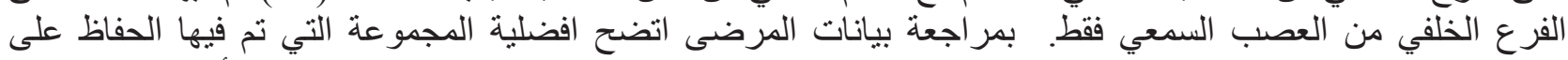

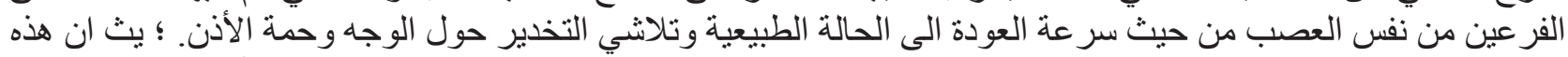

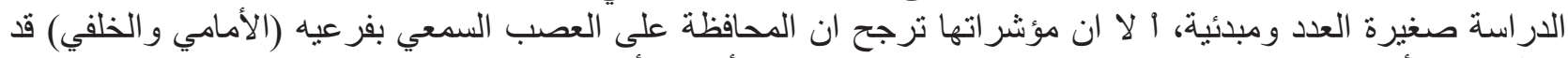
يعطي نتائج أفضل من الجر احة التقليدية وهي بحاجة الى در استات أكبر أكبر للتأكد من النتائج المبدئية. 